\title{
Blended Learning, Implementasi E-Learning Di Politeknik Negeri Balikpapan
}

\author{
Drs. Armin, M.T. ${ }^{1)}$, Ali Abrar, S.Si., M.T. ${ }^{2)}$ \\ ${ }^{1}$ Jurusan Elektronika, Politeknik Negeri Balikpapan \\ email: armin@poltekba.ac.id \\ ${ }^{2}$ Jurusan Elektronika, Politeknik Negeri Balikpapan \\ email: ali.abrar@poltekba.ac.id
}

\begin{abstract}
In the document of Strategic Planning Year 2010 - 2014, Balikpapan State Polytechnic has set quality objectives to be achieved of which is to produce graduates who master the application of Information Technology. To achieve this goal, one of the programs that are launched is System Strengthening Program in Academic and Student Affairs with target availability of facilities gradually LMS and CMS.

LMS (Learning Management System) is growing rapidly with the progress of ICT (Information and Communication Technology) in the form of the Electronic Learning System or e-Learning System. E-Learning is the educational system that uses an electronic application to support the development of teaching and learning activities with media computer networks, intranets and the internet either. With e-Learning allows the educational process without face to face and through the development of science to students can be conducted continuously.

E-Learning models that will be implemented is Blended Learning, or learning method that combines e-Learning systems with conventional methods or face-to-face model..
\end{abstract}

Keywords: e-Learning, Blended Learning, Learning Managements System

\begin{abstract}
Abstrak
Dalam Rencana Strategis Tahun 2010 - 2014, Politeknik Negeri Balikpapan telah menetapkan sasaran mutu yang ingin dicapai di antaranya adalah menghasilkan lulusan yang menguasai aplikasi Teknologi Informasi. Untuk mencapai sasaran tersebut, salah satu program yang dicanangkan adalah Program Penguatan Sistem Akademik dan Kemahasiswaan dengan sasaran Tersedianya Fasilitas LMS dan CMS secara bertahap.

LMS (Learning Management System) berkembang pesat seiring kemajuan TIK (Teknologi Informasi dan Komunikasi) dalam bentuk Sistem Pembelajaran Secara Elektronik atau e-Learning System. E-Learning adalah sistem pendidikan yang menggunakan aplikasi elektronik untuk mendukung pengembangan kegiatan belajar mengajar dengan media jaringan komputer, baik intranet maupun internet. Dengan e-Learning memungkinkan terjadinya proses pendidikan tanpa melalui tatap muka langsung dan pengembangan ilmu pengetahuan kepada mahasiswa bisa dilakukan secara terus menerus.

Model e-Learning yang diimplementasikan adalah Blended Learning, atau metode pembelajaran yang menggabungkan antara sistem e-Learning dengan metode konvensional atau tata muka (face-toface).
\end{abstract}

Kata Kunci: e-Learning, Blended Learning, Learning Managements System 


\section{Pendahuluan}

Seiring dengan perkembangan Teknologi Informasi dan Komunikasi (TIK) yang semakin pesat dan cepat, kebutuhan akan suatu konsep dan mekanisme belajar mengajar berbasis TIK menjadi tidak terelakkan lagi. Konsep yang dikenal dengan sebutan eLearning membawa pengaruh terjadinya proses transformasi pendidikan konvensional ke bentuk digital, baik secara isi dan sistemnya. Saat ini konsep e-Learning sudah banyak diterima oleh masyarakat dunia, terbukti dengan maraknya implementasi eLearning di lembaga pendidikan maupun industri.

Selama ini banyak perguruan tinggi yang proses pembelajarannya masih bersifat konvensional. Dengan kata lain bahwa proses belajar mengajar antara mahasiswa dengan dosen hanya dapat dilakukan dengan syarat terjadinya pertemuan antara mahasiswa dengan dosen di dalam ruang kelas. Jika pertemuan ini tidak terjadi maka secara otomatis proses pembelajaran pun tidak dapat dilaksanakan.

Selain itu proses transfer ilmu pengetahuan hampir sepenuhnya dilakukan di dalam ruang kelas yang menyebabkan transfer ilmu pengetahuan berhenti jika pertemuan tidak terjadi. Keadaan seperti ini jelas dapat menghambat proses pembelajaran di kampus yang dapat berakibat berkurangnya pemahaman mahasiswa terhadap suatu materi pelajaran.

Politeknik Negeri Balikpapan, sebagai perguruan tinggi baru yang belum memiliki banyak fasilitas di bidang TIK, dalam Rencana Strategis Tahun 2010 2015 telah menetapkan sasaran mutu yang ingin dicapai di antaranya adalah menghasilkan lulusan yang menguasai aplikasi Teknologi Informasi. Untuk mencapai sasaran tersebut, salah satu program yang dicanangkan adalah Program Penguatan Sistem Akademik dan Kemahasiswaan dengan sasaran Tersedianya Fasilitas LMS dan CMS secara bertahap.
Dalam rangka mencapai sasaran di atas, pada Tahun Anggaran 2013 Politeknik Negeri Balikpapan melalui UPT Sistem Informasi telah melaksanakan kegiatan Pengembangan Aplikasi LMS. Untuk melaksanakan kegiatan ini, telah dibentuk Tim PengembanganAplikasi LMS. Tim ini telah melaksanakan serangkaian kegiatan, tetapi karena keterbatasan dana, pekerjaan tim ini hanya sampai pada rekomendasi tentang model

LMS yang dianggap paling tepat untuk Politeknik Negeri Balikpapan.

Dengan latar belakang seperti di atas, maka penelitian ini dimaksudkan untuk menindaklanjuti rekomendasi dari Tim Pengembangan Aplikasi LMS seperti tersebut di atas, yaitu dalam rangka mengembangkan LMS di Politeknik Negeri Balikpapan. Model LMS yang akan diimplementasikan adalah Sistem Pembelajaran Secara Elektronik atau Sistem e-Learning yang digabungkan dengan Sistem Pembelajaran Konvensioanl (tatap muka). Sistem pembelajran ini dikenal sebagai Blended Learning.

Tujuan penelitian ini adalah untuk mengimplementasikan sistem Blended Learning yang berbasiskan web untuk memaksimalkan pencapaian tujuan pembelajaran yang dilakukan dosen dan mahasiswa.

\section{Kajian Literatur}

E-learning adalah singkatan dari Electronic Learning, merupakan cara baru dalam proses belajar mengajar yang menggunakan media elektronik khususnya internet atau intranet sebagai sistem pembelajaranya. Istilah e-learning mengandung pengertian yang sangat luas, sehingga banyak ahli mencoba menguraikan pengertian dari sudut pandang masingmasing, diantaranya: E-learning merupakan suatu jenis belajar mengajar yang memungkinkan tersampaikannya bahan ajar ke mahasiswa dengan menggunakan media 
internet, intranet, komputer atau media jaringan komputer lain.

Sejarah Perkembangan E-learning

E-learning atau pembelajaran elektronik pertama kali diperkenalkan oleh Universitas Illionis di Urbana-Champaigndengan menggunakan sistem instruksi berbasis komputer (computer-assisted instruction) dan komputer bernama PLATO. Sejak saat itu, perkembangan e-learningberkembang sejalan dengan perkembangan dan kemajuan teknologi. Berikut perkembangan e-learning dari masa ke masa:

- Tahun 1990 : Era CBT (ComputerBased Training) di mana mulai bermunculan aplikasi e-learning yang berjalan dalam PC standlone ataupun berbentuk kemasan CDROM. Isi materi dalam bentuk tulisan maupun multimedia (Video dan Audio) dalam format mov, mpeg-1, atau avi.

- Tahun 1994 : Seiring dengan diterimanya CBT oleh masyarakat sejak tahun 1994 CBT muncul dalam bentuk paket-paket yang lebih menarik dan diproduksi secara massal.

- Tahun 1997 : LMS (Learning Management System). Seiring dengan perkembangan teknologi internet, masyarakat di dunia mulai terkoneksi dengan internet. Kebutuhan akan informasi yang dapat diperoleh dengan cepat mulai dirasakan sebagai kebutuhan mutlak dan jarak serta lokasi bukanlah halangan lagi. Dari sinilah muncul LMS. Perkembangan LMS yang makin pesat membuat pemikiran baru untuk mengatasi masalah interoperability antar LMS yang satu dengan lainnya secara standar. Bentuk standar yang muncul misalnya standar yang dikeluarkan oleh AICC (Airline Industry CBT Commettee), IMS, IEEE LOM, ARIADNE, dan sebagainya.

- Tahun 1999 sebagai tahun Aplikasi Elearning berbasis Web. Perkembangan LMS menuju aplikasi e-learning berbasis Web berkembang secara total, baik untuk pembelajar (learner) maupun administrasi belajar mengajarnya. LMS mulai digabungkan dengan situs-situs informasi, majalah dan surat kabar. Isinya juga semakin kaya dengan perpaduan multimedia, video streaming serta penampilan interaktif dalam berbagai pilihan format data yang lebih standar dan berukuran kecil.

Melihat perkembangan e-learning dari dari masa ke masa yang mengikuti perkembangan teknologi, maka dapat disimpulkan bahwa elearning akan menjadi sistem pembelajaran masa depan. Alasan efektivitas dan fleksibelitas akan menjadi alasan utama.

\section{Keuntungan E-learning}

Keuntungan lain belajar dengan metode e-learning adalah menghemat waktu, menghemat biaya perjalanan, menghemat biaya pendidikan, menjangkau wilayah geografis yang luas dan melatih kemandirian para pelajar dalam mendapatkan ilmu pengetahuan. Berikut ini beberapa tips dalam pemanfaatan e-learning:

a. E-learning lebih dari sekedar e-training. Misalnya tidak dalam ruang kelas, ketika di luar kelas melalui pencarian informasi melalui media e-learning, termasuk komunikasi, kolaborasi dan berbagi pengetahuan.

b. Kompleks, rumit, interaktif, instruksional, banyak biaya untuk multimedia e-learning, waktu yang lama untuk membangun, dan kemungkinan perangkat komputer yang sudah tidak up-to-date dengan perkembangan terakhir. Dalam banyak kasus, solusi termudah adalah adanya respon yang cepat dari pengelola, termasuk penyediaan kebutuhan pembelajaran.

c. Komunikasi dan kolaborasi adalah kuncinya. Pembelajaran adalah suatu aktivitas sosial, dan terkadang pembelajar akan lebih tenang ketika mengikuti proses pembelajaran yang melibatkan sekian banyak komunitas online dan jaringan, dan dengan 
memperkuat kolaborasi diantara para pembelajar dimana kita dapat saling bertukar bahan. Yakinkan diri anda bahwa anda memang menyediakan peluang dan kesempatan bagi banyak orang untuk komunikasi, berkolaborasi dan berbagi pengetahuan.

d. Kombinasikan. Banyak solusi pembelajaran formal terkadang bekerja ketika mereka dikombinasikan (campuran) dengan hal -hal tradisional, yaitu aktivitas face-to-face, untuk membentuk solusi campuran. Cara ini akan memberikan pengalaman pembelajaran yang lebih lengkap dan bervariasi bagi siapa saja yang perlu bekerja dalam program pembelajaran sepanjang waktu.

e. Pembelajaran harus diawali dari kebutuhan individu. Kita menemukan apa yang diperlukan oleh mahasiswa tentang kebutuhan mereka untuk belajar dan temukan pula bagaimana, dimana atau kemana dan kapan mereka menginginkan belajar. Kemudian rancang solusi pembelajaran yang dapat membantu mereka.

f. Dibangun, tapi belum tentu wajib digunakan. Yang perlu diperhatikan, jika kita sudah menciptakan solusi dalam e-learning, lalu memaksakan para mahasiswa untuk datang beramai-ramai dan menggunakannya. Intinya, mahasiswa perlu melihat dan membuktikan e-learning sebagai sesuatu yang membawa keuntungan bagi mereka dan memantapkan langkah mereka dalam belajar.

g. E-learning harus disesuaikan dengan kondisi kampus bersangkutan. Kita akan melihat banyak perbedaan di setiap kampus. Maka, e-learning harus disesuaikan dengan sasaran-sasaran bisnis, budaya kampus, keinginan-keinginan para dosen dan mahasiswa dan gaya belajar setiap individu. Dengan memperhatikan faktorfaktor itu, kita akan dapat merancang solusi e-learning yang paling cocok bagi sebuah lembaga pendidikan.

\section{Metode Penelitian}

Metode yang digunakan pada penelitian ini adalah:

\section{a. Pengumpulan Bahan Ajar}

Bahan ajar ini digunakan sebagai isi dari sistem yang akan dikembangkan. Bahan ajar dikumpulkan dari setiap pengajar mata kuliah yang telah dibuat dalam bentuk lembar kerja.

\section{b. Pengembangan Sistem Blended Learning}

Dalam pengembangan sistem Blended Learning ini, metode yang digunakan adalah SDLC (System Development Life Cycle) yang memiliki beberapa tahapan pengembangan. Pada tahap analisis menggunakan tools berbasis Objek yaitu UML (Unified Modelling Language ) dan pada tahap desain dan pengembangan menggunakan Moodle CMS (Content Management System).

\section{Tempat Penelitian}

Penelitian dengan judul Blended Learning, Implementasi e-Learning di Poltekba ini dilakukan pada jaringan komputer Politeknik Negeri Balikpapan, menggunakan fasilitas dan ruangan UPT Sistem Informasi.

Tahap Penelitian

Penelitian ini dilaksanakan selama 8 (delapan) bulan. Adapun tahap-tahap penelitan adalah: persiapan penelitian, perencanaan sistem, pengumpulan data dari dosen, instalasi dan kustomisasi sistem, Input Data Sistem, Uji Coba Sistem, Evaluasi Sistem, Implementasi Sistem, Pemantauan dan Peningkatan Sistem, dan pembuatan laporan.

\section{Hasil dan Pembahasan}

Pada penelitian pendahuluan yang dilakukan adalah: 
a. Pemilihan program aplikasi yang akan digunakan sebagai LMS (Learning Management System). Hal ini bertujuan untuk mencari aplikasi yang paling tepat dengan situasi dan kondisi saat ini di Politeknik Negeri Balikpapan, baik dari sisi infrastruktur, karakteristik SDM pengguna nantinya, maupun juga dari sisi legalitas software.

Setelah mempelajari beberapa jenis aplikasi yang banyak digunakan di dunia pendidikan, maka didapati aplikasi yang paling banyak digunakan adalah Moodle.

b. Setelah memilih versi Moodle yang tepat, maka penelitian selanjutnya melakukan instalasi pada Personal Computer (PC) server yang telah disediakan.

PC server yang digunakan dalam penelitian ini dirakit dengan spesifikasi komponen sebagai berikut: Prosesor (CPU) Dual Core 1.5 GHz, RAM 2 GB, Hardisk 500 GB, Monitor 16 Inci, Casing Advance, VGA + Sound Card Internal, dan Mouse + Keyboard.

Sedangkan pada penelitian utama, dilakukan kegiatan-kegiatan seperti berikut ini:

Langkah pertama adalah menginstall aplikasi Moodle pada PC Server yang telah disiapkan dan dilanjutkan dengan melakukan kustomisasi pada aplikasi Moodle tersebut untuk disesuaikan dengan kondisi nyata di Politeknik Negeri Balikpapan.

a. Menambahkan administrator

Dalam pengembangannya sebagai Blended Learning Poltekba, dibutuhkan setidaknya lebih dari satu administrator untuk mengatur dan mengontrol jalannya Blended learning Poltekba. Untuk itu administrator utama perlu menambah beberapa administrator baru agar dapat membantunya.

b. Mengganti logo dengan logo Blended Learning Poltekba
Karena menggunakan tema dari Moodle, perlu dilakukan beberapa penyesuaian agar tampilan lebih sesuai dengan Blended Learning Poltekba itu sendiri. Maka dari itu, logo yang telah disediakan Moodle diganti dengan logo Blended Learning Poltekba.

\section{c. Menetapkan user sebagai Teacher (Dosen)}

Sesuai dengan fungsinya sebagai LMS, Blended Learning Poltekba memerlukan user yang berperan sebagai Dosen dalam pelaksanaannya. Tugas dosen disini sama dengan dosen pada umumnya, yaitu: memberikan materi dan referensinya, memberikan tugas-tugas, membuat kuis, dll. Untuk itu administrator bertugas untuk mengatur dan menetapkan user yang akan berperan sebagai dosen.

\section{d. Menambahkan banyak user sekaligus}

Untuk menambahkan banyak user sekaligus, Moodle menyediakan fitur Upload user. Fitur ini digunakan untuk menambahkan banyak user dengan cara meng-upload sebuah file yang berisikan form user dalam bentuk ekstensi CSV.

\section{e. Menghilangkan logo Moodle di footer}

Dengan adanya logo Moodle di footer kurang sesuai dengan tema Blended Learning Poltekba, maka logo tersebut perlu dihilangkan.

\section{f. Menambahkan Menubar}

Untuk memudahkan penggunaan Blended Learning Poltekba, maka perlu penambahan menubar pada halaman Blended Learning Poltekba.

\section{g. Mengubah tampilan halaman login}

Halaman login sangat standar, maka perlu dilakukan modifikasi halaman login tersebut agar terlihat lebih sesuai dengan Blended Learning Poltekba. 


\section{h. Mengubah Nama Domain}

Karena pada saat penginstalan masih menggunakan nama moodle, maka dirasa perlu untuk merubah nama domain untuk menyesuaikan dengan nama Blended Learning Poltekba (blp).

Dari kustomisasi aplikasi Moodle diperoleh hasil tampilan halaman depan seperti gambar berikut ini.

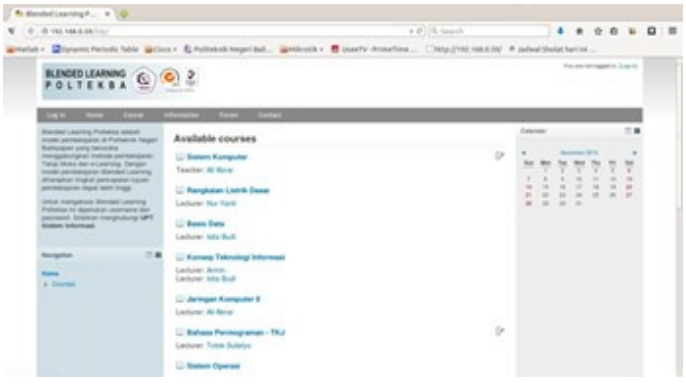

Langkah berikutnya adalah mengumpulkan dan memasukkan data-data mata-mata kuliah yang mengisi aplikasi Blended Learning Poltekba. Proses ini masih akan terus dilakukan sesuai dengan proses perkuliahan di Poltekba.

Saatpenelitian ini berakhirtelah dimasukkan data mata kuliah sebanyak 30 mata kuliah, yaitu Jurusan Teknik Elektronika 27 mata kuliah, Jurusan Teknik Mesin Alat Berat 2 mata kuliah, dan Jurusan Tata Boga 1 mata kuliah.

Langkah selanjutnya lagi adalah membuatkan username semua dosen dan mahasiswa Politeknik Negeri Balikpapan yang menjadi pengguna aplikasi Blended Learning Poltekba. Langkah ini akan terus dilakukan sesuai proses akademik yang terjadi di Poltekba.

Ketika tulisan ini dibuat jumlahdata dosen dan mahasiswa (user) yang sudah dimasukkan berjumlah 381 user dengan rincian 7 orang dosen dan 374 mahasiswa.

\section{Kesimpulan}

Dari langkah-langkah penelitian yang sudah dilakukan, tampak bahwa sebagai aplikasi Learning Management System (LMS), Moodle menawarkan banyak fasilitas yang sangat berguna dalam proses pembelajaran secara elektronik (e-Learning). Fasilitas-fasilitas ini perlu terus dieksplorasi untuk makin meningkatkan kemampuan sistem e-Learning di Poltekba (Blended Learning Poltekba).

Dari penelitian ini juga dapat disimpulkan bahwa untuk mengimplementasikan LMS di Poltekba yang memuat semua mata kuliah yang ada memerlukan upaya dan waktu yang lebih banyak. Hal ini tampak dari masih banyaknya mata kuliah yang belum sempat dimasukkan ke dalam sistem yang dikembangkan.

\section{Daftar Pustaka}

Ahmed Al-Hunaiyyan. (2007). Blended ELearning Design: Discussion of Cultural Issues. International Journal of Cyber Society and Education, Pages 17-32, Vol. 1, No. 1, March 2008.

Atik Ariesta. 2012. Kajian Learning Management System Dengan Qualitative Weight And Sum (Qws): Studi Kasus D3 Unggulan Universitas Budi Luhur. BIT VOL9 No 2 September 2012.

Sukamto, Wahyu Sulistyo (dkk). (2011). Pemanfaatan E-Learning Sebagai Pendukung Program Polines Smartcampus. Politeknik Negeri Semarang. Jurnal Informatika Vol 5, No. 2, Juli 2011.

Sukardi, Prof., Ph.D. (dkk). (2007).

Pengembangan e-learning UNY. Lembaga Penelitian Universitas Negeri Yogyakarta Yogyakarta. 